\title{
A randomised, double-blind, placebo-controlled trial of L-carnitine in suspected acute myocardial infarction
}

\author{
RB Singh, MA Niaz, P Agarwal, R Beegum, SS Rastogi, DS Sachan
}

\begin{abstract}
Summary
In a randomised, double-blind placebocontrolled trial, the effects of the administration of oral L-carnitine $(2 \mathrm{~g} /$ day) for 28 days were compared in the management of 51 (carnitine group) and 50 (placebo group) patients with suspected acute myocardial infarction. At study entry, the extent of cardiac disease, cardiac enzymes and lipid peroxides were comparable between the groups, although both groups showed an increase in cardiac enzymes and lipid peroxides. At the end of the 28-day treatment period, the mean infarct size assessed by cardiac enzymes showed a significant reduction in the carnitine group compared to placebo. Electrocardiographic assessment of infarct size revealed that the QRS-score was significantly less in the carnitine group compared to placebo $(7.4 \pm 1.2$ vs $10.7 \pm 2.0)$, while serum aspartate transaminase and lipid peroxides showed significant reduction in the carnitine group. Lactate dehydrogenase measured on the sixth or seventh day following infarction showed a smaller rise in the carnitine group compared to placebo. Angina pectoris (17.6 vs $36.0 \%$ ), New York Heart Association class III and IV heart failure plus left ventricular enlargement $(23.4$ vs $36.0 \%$ ) and total arrhythmias (13.7 vs $28.0 \%$ ) were significantly less in the carnitine group compared to placebo. Total cardiac events including cardiac deaths and nonfatal infarction were $15.6 \%$ in the carnitine group vs $26.0 \%$ in the placebo group. It is possible that L-carnitine supplementation in patients with suspected acute myocardial infarction may be protective against cardiac necrosis and complications during the first 28 days.
\end{abstract}

Keywords: carnitine, acute myocardial infarction, cardiac enzyme

Myocardial ischaemia is a dynamic process associated with inadequate coronary blood flow. ${ }^{1}$ Carnitine is found in high concentrations in cardiac muscle and it serves several important physiological functions in the heart. ${ }^{1-3}$ Hypocarnitinemia and carnitine deficiency in the myocardial tissue has been observed in laboratory animals during experimental ischaemia as well as in patients with heart disease. ${ }^{3-8}$ There is a reduction in free carnitine in the myocardium during ischaemia whereas there is an increase in acetyl and long-chain acyl carnitine levels. ${ }^{9}$ However, if the ischaemia is prolonged, total carnitine also decreases. In one study in patients with advanced heart disease, ${ }^{4}$ myocardial free carnitine was only $60 \%$ of that of control subjects. Carnitine deficiency in the myocardium has also been described in patients dying of acute myocardial infarction. ${ }^{3}$ The deficiency was more marked in the infarcted portion of the myocardium than in healthy myocardium. ${ }^{3}$ In another study, ${ }^{7}$ a myocardial free carnitine below $6.5 \mathrm{nmol} / \mathrm{g}$ noncollagenous protein was associated with a marked decline in ejection fraction compared to controls with a mean free carnitine level of $9.7 \mathrm{nmol} / \mathrm{g}$. Recent studies show that even in the presence of normal carnitine, long chain acylcarnitine levels are significantly elevated during myocardial ischaemia which may have an adverse effect upon myocardial function. ${ }^{10,11}$ The significant relationship between the concentrations of carnitine and its derivatives and myocardial function and the reduction in free carnitine during ischaemia, form the basis for the hypothesis that exogenous carnitine supplementation may minimise long-chain acylcarnitine accumulation and cardiac necrosis, as well as improving cardiac metabolism and function in patients with ischaemic heart disease. ${ }^{11-15}$ Carnitine administration has been reported to be beneficial in patients with angina, ${ }^{12,13}$ chronic myocardial ischaemia, and recent myocardial infarction. ${ }^{14}$ In this Indian study of infarct survival we report, possibly for the first time, the effect of L-carnitine administration on cardiac enzymes and lipid peroxides in patients with suspected acute myocardial infarction in a randomised trial.

\section{Patients and methods}

The study was conducted in the coronary care unit of the Medical Hospital and Research Centre, Moradabad, India, which is a primary and secondary care centre. Over a period of one year, 112 patients were admitted to the unit with a clinical diagnosis of suspected acute myocardial infarction. Patients were eligible for the study if they were judged likely to have 
had an acute infarction with onset of symptoms in the preceding 24 hours. No electrocardiographic inclusion criteria were specified. There were no specific exclusion criteria, although patients who were unable or unwilling to give verbal consent $(n=4)$, and those admitted more than 24 hours after the onset of symptoms $(n=7)$, were excluded.

Acute myocardial infarction was diagnosed ${ }^{16}$ in the presence of symmetrical ST-segment elevation of $>1 \mathrm{~mm}$ from baseline in limb leads or of $>2 \mathrm{~mm}$ in chest leads or $\mathrm{T}$-wave inversions with or without $Q$ waves in a 12-lead electrocardiogram in association with an increase in creatine kinase and serum aspartate transaminase of at least twice the upper limit of normal on serial examinations $(n=81)$. Suspected or possible acute myocardial infarction was also diagnosed on the basis of a convincing history of cardiac chest pain accompanied by an increase in cardiac enzymes of less than twice the upper limit of normal and electrocardiographic abnormalities that were suggestive of acute myocardial infarction $(n=10)$. Unstable angina was diagnosed in the presence of cardiac chest pain for $>30$ minutes without a significant increase in enzymes or diagnostic electrocardiographic changes or a combination of these $(n=6)$. Noncardiac chest pain was diagnosed in the absence of all of the above manifestations of coronary artery disease $(n=4)$.

\section{TREATMENTS}

Identical capsules for active and placebo treatments were prepared in the Heart Research Laboratory. The test drug L-carnitine is marketed under the trade name Carnitor by Elder Pharmaceuticals Limited (Bombay, India). Each tablet contained $330 \mathrm{mg}$ L-carnitine. Patients in the treatment group were given two tablets of carnitine in capsules tid $(1.98 \mathrm{~g} /$ day $)$. The placebo capsules contained $100 \mathrm{mg} /$ day of aluminium hydroxide. Compliance was monitored by counting the number of capsules returned by the patients on follow-up visits or each day during hospitalisation.

\section{STUDY DESIGN}

After giving verbal consent, the patients with suspected acute myocardial infarction were randomised to receive either $\mathrm{L}$-carnitine or placebo supplied in identical capsules and bottles.

The aim was to test the effect of carnitine supplementation on cardiac enzymes, electrocardiographic infarct size, and complications in patients with suspected acute myocardial infarction during the first 28 days after infarct. Other treatments, such as trinitrates, aspirin, and beta-blockers, were administered to both groups of patients as appropriate. The physician treating the patients and recording clinical data was blind to the assigned treatment regimens during the 28-day study. Patients remained in the hospital for 7-15 days. during hospitalisation. Blood pressures were measured in the right arm after 5 minutes rest in a supine position. Phase $V$ Korotkoff sounds were recorded for diastolic blood pressure. A systolic blood pressure $<90 \mathrm{mmHg}$ was diagnostic of hypertension. Patients who smoked one or more cigarettes per day were considered to be smokers. Hypercholesterolemia was defined as a serum cholesterol $>5.2 \mathrm{mmol} / \mathrm{l}$. Diabetes mellitus and previous coronary artery disease were diagnosed on the basis of available records.

A 12-lead electrocardiogram was recorded daily for one week and then on alternate days and whenever indicated during the period of hospitalisation. Heart rate and arrhythmias were recorded from resting electrocardiogram and 24-hour monitoring. Arrhythmias were treated with drugs in the presence of at least 8 ventricular actopics/minute, which may have been uni or multifocal or three consecutively. Angina pectoris was recorded in patient diaries; when cardiac chest pain persisted for more than one minute it was relieved or diminished by taking sublingual nitroglycerine. A record of nitroglycerine/trinitrate consumption was also kept in the patient diaries. Blood pressure was recorded at least twice daily. Heart failure was recorded on the basis of criteria of the New York Heart Association as a dilated heart demonstrated by radiologic or electrocardiographic (or both) dilatation of the left ventricle. Heart enlargement was diagnosed on the basis of radiologic and/or electrocardiographic examination. Clinical data, complications, drug intake, smoking, alcohol intake were recorded on a case record form by the treating physician. Information on 28-day survival was also obtained from hospital and health authority records. Total cardiac events included nonfatal myocardial infarction (diagnostic criteria mentioned above) and cardiac deaths. Counselling for routine physical activity, mental stress, and maintenance of regular bowel movements was provided in both groups if required.

\section{SIZE OF INFARCTION}

The size of the acute myocardial infarction was assessed on the basis of electrocardiographic changes and cardiac enzyme activity. A blood sample for creatine kinase and its muscle brain (MB) fraction was drawn every four hours within the first 24 hours, every six hours on the second day and once daily for the last eight days. Infarct size was considered as the product of a proportionality constant $K$, body weight and enzyme release measured by the area under the curve of the serial enzyme concentration dosages according to the method of Sobel with the correction of Tansey. The $K$ values are $5.9 \times 10^{-1}$ for total creatine kinase and 4.1 for the MB fraction.

Electrocardiographic assessment of infarct size was done with the help of the 12-lead electrocardiograms of patients before therapy, then on the third, seventh and tenth days of treatment. Electrocardiograms showing bundle branch block and paced rhythm were not analysed. Based on a method derived from 
Marako, the summated Q-wave depths and $R$-wave heights in leads $V_{1}$ to $V_{6}$ for anterior infarction were compared between the two groups.

\section{LABORATORY DATA}

A venous blood sample was drawn immediately after admission to hospital and analysed for blood counts, haemoglobin, urea, glucose, cardiac enzyme activity and carnitine. ${ }^{18}$ Lactate dehydrogenase and aspartate transaminase were analysed daily during the first week of hospitalisation. All analyses were performed by technicians unaware of the treatment groups of the patients.

A spectrophotometric method ${ }^{17}$ for quantitative assay of plasma lipid peroxides free of interference from sialic acid was used and lipid peroxidation was determined by the thiobarbituric acid reactivity of malonyldialdehyde. Butylated hydroxytoluene and $30 \%$ trichloroacetic acid were added to plasma to develop the reaction. The thiobarbituric acid was dissolved in sodium sulphate solution and the liberation of lipid peroxide and colour reaction were measured simultaneously. Absorbance was read by UV-visible spectrophotometry.

\section{STATISTICAL ANALYSES}

Data were analysed on the basis of intention-totreat. In the all-outcome analysis, the last available clinical or laboratory data were incorporated for patients who were lost to follow-up or died. Only p-values $<0.05$ in two-tailed

Table 1 Patient characteristics on entry to study

\begin{tabular}{lrr}
\hline & $\begin{array}{c}\text { Carnitine } \\
(n=51)\end{array}$ & $\begin{array}{r}\text { Placebo } \\
(n=50)\end{array}$ \\
\hline Male sex (n) (\%) & $46(90.2)$ & $45(90.0)$ \\
Mean age (years) (SD) & $49.2(5.5)$ & $50.5(6.2)$ \\
Mean body weight (kg) (SD) & $65.1(6.4)$ & $65.0(5.8)$ \\
Mean time from symptom onset (h) (SD) & $10.2(1.8)$ & $10.8(2.4)$ \\
History & \multicolumn{1}{c}{} \\
previous acute myocardial infarction & $10(19.6)$ & $11(22.0)$ \\
previous angina pectoris & $12(23.5)$ & $9(18.0)$ \\
known hypertension & $12(23.5)$ & $10(20.0)$ \\
known diabetes & $8(15.6)$ & $7(14.0)$ \\
known hypercholesterolemia & $6(11.7)$ & $7(14.0)$ \\
current smoker & $10(19.6)$ & $10(20.0)$ \\
ex-smoker & $8(15.6)$ & $7(14.0)$ \\
on atenolol (80-120 mg/day) & $12(23.5)$ & $13(26.0)$ \\
on captopril (25-50 mg/day) & $10(19.6)$ & $10(20.0)$ \\
on aspirin (100-150 mg/day) & $19(37.2)$ & $18(36.0)$ \\
Final diagnosis & & \\
Q-wave myocardial infarction & $41(80.4)$ & $40(80.0)$ \\
non-Q wave myocardial infarction & $6(11.7)$ & $4(8.0)$ \\
angina pectoris & $2(3.9)$ & $4(8.0)$ \\
other diagnosis & $2(3.9)$ & $2(4.0)$ \\
Infarction site & & \\
anterior & $25(49.0)$ & $24(48.0)$ \\
inferior/posterior & $20(39.2)$ & $21(42.0)$ \\
universal & $6(11.7)$ & $5(10.0)$ \\
Ventricular ectopic (>8/minute) & $8(15.6)$ & $8(16.0)$ \\
Left ventricular hypertrophy & $8(15.6)$ & $7(14.0)$ \\
Creatine kinase (IU) & $204.2(32.2)$ & $201.6(28.6)$ \\
Drug therapy on admission & & \\
atenolol (100-150 mg/day) & $20(39.2)$ & $21(42.0)$ \\
diltiazam (60-180 mg/day) & $24(47.0)$ & $23(46.0)$ \\
nitrates (20-60 mg/day) & $49(96.0)$ & $50(100)$ \\
aspirin (100-150 mg/day) & $48(94.0)$ & $50(100)$ \\
\hline & & \\
& & \\
& &
\end{tabular}

$t$-tests were considered statistically significant. Two-sample $t$-tests using analysis of variance and Z-score tests for proportions were used to assess statistical significance between the two groups.

\section{Results}

Of 101 subjects who volunteered to participate in the study, 51 received carnitine (approximately $2 \mathrm{~g} /$ day) and 50 the placebo in identical capsules and bottles. The comparability of the two treatment groups was good as shown in table 1.

There were no withdrawals and smoking was stopped by all the patients in both groups. There were no side effects due to carnitine therapy, except for loose stools in three patients. Although initial drug therapy was comparable between the groups, on day 28 consumption of nitrate, furosemide and antiarrhythmics was higher in the placebo group.

\section{INFARCTION SIZE}

Table 2 shows that myocardial infarct size was significantly less in the carnitine group compared to the placebo group as revealed by the levels of creatine kinase and creatine kinaseMB. Electrocardiographic assessment of infarct size in the carnitine group also showed a significant reduction compared to the placebo group. The QRS scores during the first 10 days of follow-up were significantly lower in the carnitine group than in the placebo group (table 2).

\section{LABORATORY DATA}

At entry to study, cardiac enzymes and lipid peroxides (thiobarbituric acid reactive substances) were comparable between the two groups. An increase in lipid peroxide is the indicator of cell membrane damage due to free radical stress in acute myocardial infarction. After treatment, the carnitine group showed a greater reduction in aspartate transaminase and lipid peroxides and a smaller rise in lactate dehydrogenase compared to the placebo group (table 3).

\section{COMPLICATIONS AND CARDIAC EVENTS}

Angina pectoris, the total number of cases with poor left ventricular function (class III and IV heart failure plus left ventricular enlargement), and total arrhythmias were significantly less in the carnitine group compared to the placebo group. Total cardiac events including nonfatal infarction and cardiac deaths were significantly fewer in the carnitine group compared to placebo during the 28 days of follow-up (table 4).

\section{Discussion}

In acute myocardial infarction, the ischaemic damage and metabolic reactions are so rapid that benefits of treatment are difficult to achieve if the treatment is not given immediately after infarction. ${ }^{19}$ The majority of our patients were given carnitine within 10 hours of the onset of symptoms. The results showed that carnitine 
Table 2 Cardiac enzyme activity and electrocardiographic data showing infarct size. Values are means (standard deviations)

\begin{tabular}{|c|c|c|}
\hline & $\begin{array}{l}\text { Carnitine } \\
(n=51)\end{array}$ & $\begin{array}{l}\text { Placebo } \\
(n=50)\end{array}$ \\
\hline \multicolumn{3}{|l|}{ Creatine kinase } \\
\hline Size of necrosis (gram equivalents) & $95.5(23.6)^{\star \star}$ & $116.2(26.2)$ \\
\hline $\begin{array}{l}\text { Maximum latent period before } \\
\text { enzyme peak (min) }\end{array}$ & $1192.5(305)^{\star}$ & $1308(328)$ \\
\hline Enzyme peak (IU/l) & $1.48(0.78)^{\star}$ & $1.88(0.92)$ \\
\hline Area under the curve & $3275(955)^{\star \star}$ & $4307(1150)$ \\
\hline \multicolumn{3}{|l|}{ MB creatine kinase } \\
\hline Size of necrosis (gram equivalents) & $58.6(16.6)^{\star \star}$ & $73.3(21.5)$ \\
\hline $\begin{array}{l}\text { Maximum latent period before } \\
\text { enzyme peak (min) }\end{array}$ & $1085(254)^{\star}$ & $1180(265)$ \\
\hline Enzyme peak (IU/l) & $1.32(0.4)^{\star}$ & $1.55(0.6)$ \\
\hline Area under the curve & $2790(715)$ & $3110(680)$ \\
\hline QRS - score & $7.4(1.2)^{\star \star}$ & $10.7(2.0)$ \\
\hline
\end{tabular}

${ }^{\star} \mathrm{p}=\left\langle 0.05,{ }^{\star \star} \mathrm{p}=<0.01\right.$. $\mathrm{p}$-value obtained by two-sample $t$-test comparing carnitine and placebo groups.

Table 3 Effect of carnitine treatment on cardiac enzymes and lipid peroxides

\begin{tabular}{llllll}
\hline & \multicolumn{2}{l}{ Carnitine group } & & \multicolumn{2}{l}{ Placebo group } \\
\cline { 2 - 3 } \cline { 5 - 6 } Enzyme & pre-Rx & post-Rx & & pre-Rx & post-Rx \\
\hline $\begin{array}{c}\text { Aspartate trans- } \\
\text { aminase (IU/1) }\end{array}$ & $170.0(15.8)$ & $124.3(10.5)^{\star}$ & $172.2(17.6)$ & $146.2(14.2)^{\star}$ \\
$\begin{array}{c}\text { Lactate dehydro- } \\
\text { genase (IU/l) }\end{array}$ & $97.5(10.5)$ & $205.0(25.6)^{\star}$ & $110.3(12.0)$ & $272.5(32.6)^{\star}$ \\
$\begin{array}{c}\text { Lipid peroxides } \\
\text { (nmol/ml) }\end{array}$ & $2.8(0.25)$ & $1.8(0.22)^{\star}$ & $2.7(0.23)$ & $2.6(0.12)^{\star}$ \\
\hline
\end{tabular}

${ }^{\star} \mathrm{p}<0.05$.

Table 4 Complications at 28 days of follow-up. Values are numbers (percentages)

\begin{tabular}{|c|c|c|c|}
\hline Complications & $\begin{array}{l}\text { Carnitine } \\
(n=51)\end{array}$ & $\begin{array}{l}\text { Placebo } \\
(n=50)\end{array}$ & $\begin{array}{l}\text { Relative risk } \\
(95 \% C L)\end{array}$ \\
\hline Angina pectoris & $9(17.6)^{\star}$ & $18(36.0)$ & $\begin{array}{l}0.49 \\
(0.98,0.24)\end{array}$ \\
\hline $\begin{array}{l}\text { NYHA Class III and IV } \\
\text { heart failure }\end{array}$ & $4(7.8)$ & $7(14.0)$ & $\begin{array}{l}0.56 \\
(1.86,0.17)\end{array}$ \\
\hline Left ventricular enlargement & $8(15.6)$ & $11(22.0)$ & $\begin{array}{l}0.71 \\
(1.61,0.31)\end{array}$ \\
\hline $\begin{array}{l}\text { Total cases with poor left } \\
\text { ventricular function }\end{array}$ & $12(23.4)^{\star}$ & $18(36.0)$ & $\begin{array}{l}0.65 \\
(1.24,0.35)\end{array}$ \\
\hline Ventricular ectopics $(>8 / \mathrm{min})$ & $6(11.7)$ & $11(22.0)$ & $\begin{array}{l}0.54 \\
(1.32,0.24)\end{array}$ \\
\hline $\begin{array}{l}\text { Ventricular ectopics } \\
(>3 \text { consecutively) }\end{array}$ & $1(1.9)$ & $3(6.0)$ & $\begin{array}{l}0.31 \\
(2.79,0.03)\end{array}$ \\
\hline Total arrhythmias & $7(13.7)^{\star}$ & $14(28.0)$ & $\begin{array}{l}0.49 \\
(1.11,0.21)\end{array}$ \\
\hline Hypotension (systolic $<90 \mathrm{mmHg}$ ) & $1(1.9)$ & $3(6.0)$ & $\begin{array}{l}0.31 \\
(2.79,0.03)\end{array}$ \\
\hline $\begin{array}{l}\text { Cardiac end points: } \\
\text { total cardiac deaths }\end{array}$ & $4(7.8)$ & $6(12.0)$ & $\begin{array}{l}0.65 \\
(1.88,0.22)\end{array}$ \\
\hline nonfatal reinfarction & $4(7.8)^{\star}$ & $7(14.0)$ & $\begin{array}{l}0.56 \\
(1.86,0.17)\end{array}$ \\
\hline total cardiac events & $8(15.6)^{\star}$ & $13(26.0)$ & $\begin{array}{l}0.60 \\
(1.62,0.27)\end{array}$ \\
\hline
\end{tabular}

${ }^{\star} \mathrm{p}=\langle 0.05$; $\mathrm{p}$-value significant by $\mathrm{Z}$ score test for proportions by comparison of carnitine group with placebo. $C L=$ confidence limits; NYHA = New York Heart Association. supplementation $(2 \mathrm{~g} /$ day) in patients with a suspected acute myocardial infarction was associated with a significant reduction in creatine kinase, creatine kinase-MB (gram equivalents) and aspartate transaminase and a smaller rise in lactate dehydrogenase, indicating lower cardiac necrosis in the carnitine group compared to placebo (table 2). Plasma levels of thiobarbituric acid reactive substances which arise due to degradation of cell polyunsaturated fatty ${ }^{17}$ acids also showed a greater reduction with carnitine compared to placebo. Since an increase in these subgroups in patients with acute myocardial infarction may be the result of cardiac damage due to over production of free radicals, ${ }^{20,21}$ the possibility exists that carnitine administration might inhibit free radical injury to myocardium. However, more studies would be necessary to confirm this hypothesis.

Apart from the reduction in infarct size indicated by cardiac enzyme activity, electrocardiographic infarct size showed a significant decline in the carnitine group compared to placebo (table 2). In one study, ${ }^{15}$ the effect of orally administered L-carnitine $(40 \mathrm{mg} / \mathrm{kg}$ daily) on the release and maximum serum concentrations of creatine kinase-MB during the first 48-72 hours was examined in 22 patients with acute myocardial infarction. Compared with untreated controls, L-carnitine supplementation was associated with a decreased release of creatine kinase-MB (465 vs $520 \mathrm{mg} / \mathrm{l}$ ) and a lower maximum value (165 vs $205 \mathrm{mg} / \mathrm{l})$. The finding that free L-carnitine concentrations in myocardial tissue from infarcted areas of patients dying of acute myocardial infarction was much lower than that from heart tissues of patients dying due to other causes, suggest that L-carnitine may have a role in limiting necrosis. ${ }^{3}$ There is some more evidence from open clinical trials ${ }^{22-24}$ that treatment with $\mathrm{L}$-carnitine caused a reduction in the area of necrosis in patients with acute myocardial infarction. In controlled trials, ${ }^{24}$ single intravenous doses of L-carnitine $(40-140 \mathrm{mg} /$ $\mathrm{kg}$ ) reduced the production of lactate in the myocardium compared to placebo-treated control subjects. In another study ${ }^{25}$ in 40 patients undergoing aorto-coronary by-pass surgery, pretreatment with L-carnitine ( $1 \mathrm{~g} /$ day) for two days and $0.5 \mathrm{~g}$ intravenously prior to surgery was associated with a reduction in lactate levels in the myocardium with a significant increase in levels of adenosine triphosphate (ATP) without such changes in the control group.

The exact mechanism of action by which L-carnitine modulates myocardial metabolism in patients with ischaemic heart disease is not known. It is possible that $\mathrm{L}$-carnitine prevents inhibition of glucose metabolism, preserves fatty acid metabolism and removes toxic longchain fatty acid metabolites from the myocardial tissue. ${ }^{1-4}$ It is not known whether Lcarnitine can scavenge free radicals generated due to the presence of a free hydroxyl group in its chemical structure. ${ }^{12}$ It seems that the availability of free carnitine stimulates betaoxidation, thereby reducing intramitrochondrial acyl-coenzyme A and increasing ATP production. ${ }^{1-4}$ The decrease in intramito- 


\section{L-carnitine: properties \\ - naturally occurring, nontoxic substance \\ - synthesised in the liver and kidneys from lysine and methionine \\ - more than $90 \%$ of body's carnitine is found in cardiac and skeletal muscle \\ - essential for fatty acid oxidation and energy production \\ - essential for the transfer of long-chain fatty acids from the cytoplasm to the mitochondria, permitting beta-oxidation and producing energy in the form of ATP \\ - enhances the oxidative utilisation of glucose, preventing lactic acid formation which is damaging to the myocardial cell \\ - prevents the inhibition of adenine nucleotide translocase, an enzyme responsible for passage of ADP and ATP, and thus improves the availability of ATP at the site of utilisation \\ - decreases lipid peroxidation which suggests that it might scavenge free radicals \\ - carnitine deficiency enhances the accumulation of fatty acids which are toxic to cell membrane in cytoplasm}

Box 1

chondrial acyl-esters may stimulate the adenine nucleotide translocase and activate the transport of ADP and ATP across the mitrochondrial membrane. ${ }^{2,26}$ Furthermore, metabolic flux through the citric acid cycle will be enhanced and the oxidative utilisation of pyruvate increased due to an increase in the availability of intramitochondrial free coenzyme $A$ and a reduction in the acetyl-coenzyme A/coenzyme A ratio. ${ }^{2}$ During ischaemia, oxidative utilisation of pyruvate helps in maintaining $\mathrm{ATP}^{26}$ which may reduce muscle necrosis. Similarly, angina may be reduced because intracellular energetics are improved by the drug which may decrease the oxygen requirement of the cell. Since carnitine has no effect on thrombosis, it should not be compared with thrombolytics, although both drugs reduce infarction size.

The improvement in myocardial necrosis in acute myocardial infarction patients with carnitine supplementation was associated with a significant decline in angina pectoris and total cardiac arrhythmias and a reduction in class III and IV heart failure and left ventricular enlargement. Although total cardiac mortality did not show a significant reduction in the carnitine group, total cardiac events were significantly fewer in the carnitine group compared to the placebo group (table 4). There seems to be strong evidence that short term ( $<30$ day) supplementation of carnitine may be beneficial in patients with ischaemic heart disease. When carnitine was administered to patients with coronary artery disease for up to

\section{Learning points}

- the role of $\mathrm{L}$-carnitine in the management of coronary artery disease especially acute myocardial infarction is not established

- in acute myocardial infarction, there is a relative or total deficiency of carnitine in the myocardium

- treatment with carnitine decreases angina pectoris, cardiac arrhythmias and left ventricular function as well as total cardiac events which may be due to reduction in infarction size

- L-carnitine might also decrease free radical stress

Box 2

30 days in doses of 1.5-6 g/day orally, exercise capacity, time to exhaustion, maximum workload and time to onset of ischaemia and angina all increased. ${ }^{27-29}$ However, there was a reduction in the degree of ST segment depression (during submaximal exercise), angina pectoris and ventricular ectopics. Results from a shortterm controlled study ${ }^{27}$ in patients with stable angina reported that $23 \%$ of patients were free of angina following four weeks of treatment with L-carnitine $(2.0 \mathrm{~g} /$ day $)$. In cardiomyopathy, carnitine therapy has been found to decrease hypertrophy and increase left ventricular ejection fraction. ${ }^{12}$ In a multicentre randomised trial, ${ }^{30} 351$ patients with acute myocardial infarction were administered Lcarnitine for 48 hours within eight hours of onset of symptoms. After a week, the reduction in $R$ voltage of the $Q R S$ complex was $15 \%$ less in the L-carnitine recipients than in patients given placebo, indicating less cardiac necrosis with carnitine, although deaths were equal. In another study ${ }^{14}$ on 160 patients after acute myocardial infarction, 81 subjects who were given carnitine for one year showed an improvement in systolic blood pressure, decrease in angina and arrhythmias and better left ventricular function. These changes were associated with significant reduction in mortality (1.2 vs $12.5 \%$, p < 0.005). A more recent study has shown that carnitine administration can modulate left ventricular remodelling in patients with acute myocardial infarction. ${ }^{31}$

The results of this Indian study on infarct survival indicate that carnitine supplementation reduces risk within the first 28 days following acute myocardial infarction and can protect against myocardial damage as well as complications such as angina, arrhythmias, left ventricular failure, and also possibly cardiac events. A larger study would be necessary to confirm our findings.
1 Camici P, Marracini P, Lorenzoni R. Metabolic markers of stress induced ischaemia. Circulation 1991; 83 (suppl III): 118.

2 Opie LE. Role of carnitine in fatty acid metabolism of normal and ischaemic metabolism. Am Heart $\mathcal{F} 1979$; 97 375-88.

3 Spagnoli LG, Corsi M, Villaschi S, Palmieri G. Maccari F.

Myocardial carnitine deficiency in acute myocardial infarction. Lancet 1982; 1: 1419-20.
4 Bohles H, Noppeney T, Akcetin Z. The effect of preoperative $\mathrm{L}$-carnitine supplementation on myocardial metabolism during aorto-coronary-bypass surgery. Curr Ther Res 1990; 39: 429-35.

5 Bressler R, Gay R, Copeland J, Bahl J, Bedotto J, Godman S. Chronic inhibition of fatty acid oxidation: new model of diastolic dysfunction. Life Sci 1989; 44: 1987-96. 
6 Pierpoint ME, Judd D, Goldenberg JF, Ring WJ. Myocardial carnitine in end stage congestive heart failure. $A m \mathcal{F}$ Cardiol 1989; 64: 56-60.

7 Regitz V, Shug AL, Fleck E. Defective myocardial carnitine metabolism in congestive heart failure secondary to dilated cardiomyopathy and to coronary, hypertensive and valvular heart diseases. Am ₹ Cardiol 1990; 65: 755-60.

8 Suzuki Y, Masamura Y, Kobayashi A, Yamazaki M, Haraday $O$, Ossawa $M$. Myocardial carnitine deficiency in chronic heart failure. Lancet 1982; 1: 116.

9 Shug AL, Thomsen JH, Folts JD, et al. Changes in tissue levels of carnitine and other metabolites during ischaemia and anoxia. Arch Biochem Biophys 1978; 187: 25-30.

10 Burkhoff D, Weiss RG, Schulman SP. Influence of metabolic substrate on heart rate, function and metabolism at different coronary flows. Am $\mathcal{F}$ Physiol 1991; 261: 741-50.

11 Corr PB, Creer MH, Yamada KA, Sciffitz JE. Prophylaxis of early ventricular fibrillation by inhibition of acylcarnitine accumulation. 7 Clin Invest 1989; 83: 927-36.

12 Goa KL, Brogoten RN. L-carnitine: a preliminary review of its pharmacokinetics and its therapeutic use in ischaemic cardiac disease and primary and secondary carnitine deficiencies in relationship to its role in fatty acid metabolism. Drug 1987; 34: 1-24.

13 Cacciatore L, Cerio R, Garimboli M, et al. The therapeutic effect of L-carnitine in patients with exercise-induced stable angina: a controlled study. Drug Exp Clin Res 1991; 17 225-35.

14 Davini P, Bigalli A, Lamanna F, Boem A. Controlled study on L-carnitine therapeutic efficacy in post infarction. Drug Exp Clin Res 1992; 18: 355-65.

15 Rebuzzi AG, Schiavoni G, Amico CM, Montenero AS, Meo F. Beneficial effects of L-carnitine in the reduction of the necrotic area in acute myocardial infarction. Drug Exp Clin Res 1984; 10: 219-23.

16 World Health Organization. Myocardial infarction community registers. Copenhagen: World Health Organization, 1976.

17 Esterbaur H, Cheeseman KH. Determination of aldehyde lipid peroxidation products. Malonaldehyde and 4hydroxynonenal. Meth Enzymol 1990; 186: 407-21.

18 Cederblad G, Linstedt $S$. A method for the determination of carnitine in the picamole range. Clin Chim Acta 1972; 37: 235-43.
19 Ceremuzynski L. Hormonal and metabolic reactions evoked by acute myocardial infarction. Circ Res 1981; 48: 765-76.

20 Bernier M, Hearge DJ, Manning AS. Reperfusion induced arrhythmias and oxygen derived free radicals. Circ Res 1986; 58: $331-40$.

21 Singh RB, Niaz MA, Shazma JP, Kumar R, Bishnoi I, Beegum R. Plasma levels of antioxidant vitamins and oxidative stress in patients with acute myocardial infarction. Acta Cardiol 1994; 49: 441-52.

22 Fern L, Galiazzo F, Siliprandi N. Carnitine:significato biochemico e medico. Progr Med 1978; 34: 709-23.

23 Liedtke AJ, Nellis SH. Effects of carnitine in ischaemic and fatty acid supplemented swine hearts. $\mathcal{F}$ Clin Invest 1979; 64 440-7.

24 Ferrari R, Cucchini F, DiLisa F, Raddino R, Bolognesi R. The effect of L-carnitine on myocardial metabolism of patients with coronary artery disease. Clin Trials $\mathcal{f} 1984 ; 21$ : 40-58.

25 Bohles H, Noppeney T, Akcetin Z, Rein J, von der Emde J. The effect of preoperative $\mathrm{L}$-carnitine supplementation on myocardial metabolism during aorto-coronary bypass surgery. Curr Ther Res 1986; 39: 429-35.

26 Siliprandi N, Di Lisa F, Toninello A. Biochemica derangements in ischaemic myocardium: the role of carnitine. G Ital Cardiol 1984; 14: 804-8.

27 Cherchi A, Lai C, Onnis E, Orani E. Propionyl carnitine in stable effort angina. Cardiovasc Drug Ther 1990; 4: 481-6.

28 Cherchi A, Lai C, Angelino F, Trucco G. Effects of $\mathrm{L}$-carnitine in exercise tolerance in chronic stable angina, multicentre, double blind randomized, placebo controlled cross over study. Int $\mathcal{F}$ Clin Pharmacol Ther Toxicol 1985; 23: 569-72.

29 Palazzuoli V, Mondillo S, Faglia S, D'Aprile N. The evaluation of antiarrhythmic ativity of $\mathrm{L}$-carnitine and propafenone. Clin Ther 1993; 142: 155-9.

30 Chiariello M, Nrevetti G, Policicclio A, Nevola E, Condorelli M. L-Carnitine in acute myocardial infarction. A multicentre randomized trial. In: Borum, ed. Clinical aspects of human carnitine deficiency, New York: Pergamon Press, 1986; pp 242-3.

31 Iliceto $\mathrm{S}$. Effects of L-carnitine administration on left ventricular remodelling after acute anterior myocardial infarction. $\mathcal{F}$ Am Coll Cardiol 1995; 26: 380-7. 